\title{
Early Hardening Process of CA Mortar Indicated by Electrical Resistivity
}

\author{
Tao WANG ${ }^{1}$, Hengqiong JIA, Shaoliang WU, Zhao WEI, Xiao XIE, Haiyan LI, \\ Hequan ZHU, Cunshan DU, and Yi SHI \\ Metals and Chemistry Research Institute, China Academy of Railway Sciences, China
}

\begin{abstract}
A non-contact electrical resistivity measurement device was employed to indicate the early hardening process of cement asphalt emulsified mortar (CA mortar). It was found that this process was analogous with the hydration process of cement and could be categorized into three parts: dissolving period, induction period and setting period. The mortar resistivity first decreased and then increased with the elapsed time. The effect of water/cement ratio (W/C), asphalt emulsified/cement ratio $(\mathrm{A} / \mathrm{C})$, cement types were also explored. Results indicated that the increase of W/C, dosages in SF (Silica fume) extended the induction period; replacement of Portland cementII with sulfoaluminate cement in CA mortar markedly increased the electrical resistivity and advanced the onset of setting period by $5 \sim 6 \mathrm{~h}$, making it possible to prepare CA mortar with high early strength, which can preventing distress such as peeling and bleeding during construction in winter and conformance to requirements in acceptance standard.
\end{abstract}

Keywords. CA mortar, hardening process, electrical resistivity, hydration

\section{Introduction}

China railway track system Itype (CRTS I) ballastless track has been widely used in Chinese high-speed railway due to its simple structure and its convenient construction and repair [1-3]. The cement asphalt emulsified mortar (CA mortar) filled in the $40 \mathrm{~mm} \sim 60 \mathrm{~mm}$ flat space between the track slab and base plate is an important filling material of CRTS I ballastless track, and CA mortar is an elastic interlayer, which plays a key role as shock absorbing of the slab track, and it consists of cement, asphalt emulsified, fine aggregate and a variety of organic admixtures. It is a high performance semi-rigid composite which combining the merits of high strength from cement paste and good elasticity from asphalt materials [4-6]. CA mortar is a highly flowable grouting material, requiring a workable time beyond $45 \mathrm{~min}$. Knowledge about the early hardening process of CA mortar is very important to control its workability during pumping, which is mainly governed by the synergic cooperation of cement hydration and asphalt emulsified breaking [7-9].

There are few studies on the early hardening process of CA mortar [10-15]. In order to further explore the change of CA mortar properties in this process, the author characterized the setting process of CA mortar by the penetrating depth of a needle

1 Corresponding author: Tao Wang: researcher, Metals and Chemistry Research Institute, China Academy of Railway Sciences E-mail:027wangtao@163.com 
using a Vicar apparatus. However, the specimens used in the test was CA paste (viz. free of fine aggregate) for the sake of testing convenience and the measurement was not real time. Electrical resistivity measurement, a method used in this paper, was primarily employed to monitor the hydration process of cement [16-18]. The works of the previously mentioned researchers have shown that electrical resistivity measurements are simple, robust and the whole process was uninterrupted.

In the paper, a non-contact electrical resistivity measurement device was used to study the effect of water/cement ratio (W/C) (containing the water in asphalt emulsified), asphalt emulsified/cement ratio (A/C) and cement types on the hardening process of CA mortar.

\section{Raw Materials, Preparation and Mix Proportions}

(1)Emulsified asphalt : cationic slow-breaking emulsified asphalt specifically manufactured for CRTS-I CA mortar(60\% of solid content); (2) Dry-mixed mortar: cement-based dry-mixed mortar with $33 \%$ by weight having a particle size < $0.075 \mathrm{~mm}$, mix proportion, Cement: sand $=1.0: 2.0$ (by mass), Portland cement II (P·II) with strength grade of 52.5 and rapid hardening sulfoaluminate cement (SAC) were used, River sand used here had a fineness modulus of 1.4 1.6; (3) defoaming agent: organic silicon; (4) air-entraining agent: rosin; (5) Silica fume (SF).

Raw material ratio by weight: dry-mixed mortar: emulsified asphalt: water: defoaming agent: air-entraining agent $=3: 1.6: 0.067: 0.0004: 0.004$, Dry-mixed mortar: $1103 \mathrm{~kg} / \mathrm{m}^{3}$.

CA mortar was prepared by a mortar mixer machine, Mixing procedure: the liquid ingredients (water, emulsified asphalt, defoaming agent), was added at first, with a mixing slowly; Then, the dry-mixed mortar was added with a mixing high speed, Finally, with a high mixing speed to complete the CA mortar preparation.

Table 1 listed all the other proportions for the experiment.

Table 1. Mix proportions of CA mortar and cement mortar

\begin{tabular}{cccccccc}
\hline & & & P•II & SAC & SF & A & S \\
\cline { 3 - 8 } NO. & W/C & A/C & & & $\mathrm{kg} / \mathrm{m}^{3}$ & & \\
\hline W1 & 0.84 & 0 & 300 & 0 & 0 & 0 & 600 \\
W2 & 0.80 & 1.6 & 300 & 0 & 0 & 480 & 600 \\
W3 & 0.84 & 1.6 & 300 & 0 & 0 & 480 & 600 \\
W4 & 0.88 & 1.6 & 300 & 0 & 0 & 480 & 600 \\
W5 & 0.84 & 1.4 & 300 & 0 & 0 & 420 & 600 \\
W6 & 0.84 & 1.8 & 300 & 0 & 0 & 540 & 600 \\
W7 & 0.84 & 1.5 & 0 & 300 & 0 & 450 & 600 \\
W8 & 0.84 & 1.6 & 0 & 300 & 0 & 480 & 600 \\
W9 & 0.84 & 1.5 & 291 & 0 & 9 & 450 & 600 \\
W10 & 0.84 & 1.6 & 282 & 0 & 18 & 480 & 600 \\
\hline
\end{tabular}

\section{Experimental Methods}

A CCR2 contactless resistivity tester was used in the experiment (Figure 1). The signal generator changed the $50 \mathrm{~Hz} \mathrm{AC}$ current into $1000 \mathrm{~Hz} \mathrm{AC}$ current, and then the $\mathrm{AC}$ current was amplified through the amplifier, and the $\mathrm{AC}$ voltage in the circuit was 
changed through the transformer. The primary coil of the transformer was composed of multi-turn coils, and the secondary coil was equivalent to a one-turn ring mold, and a ring voltage $\mathrm{V}$ was applied to the secondary coil. The new cement-based material was poured into the mold, the cyclic current I of the sample at different times was measured and recorded by a small current sensor and a computer, and the resistivity $(\rho)$ of the sample was calculated. Mixed CA mortar according to the mix ratio is in Table 1. Poured the new CA mortar rapidly into the test mold of the resistivity tester and vibrated, and then recorded the resistivity once a minute. The resistivity - time curve was obtained by recording 1d continuously [19-21].

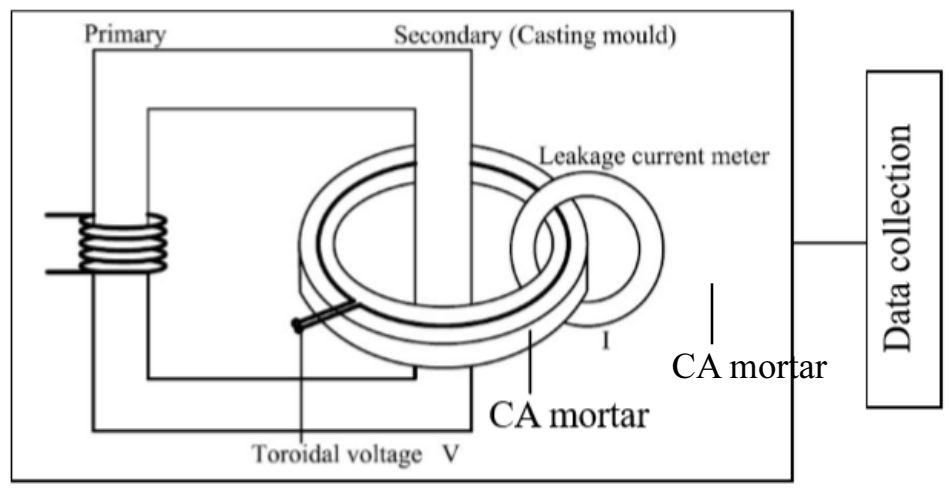

Figure 1. ACCR2 Resistivity Measurement device

\section{Results and Discussions}

\subsection{Evolvement of Electrical Resistivity during Early Hardening of CA Mortar}

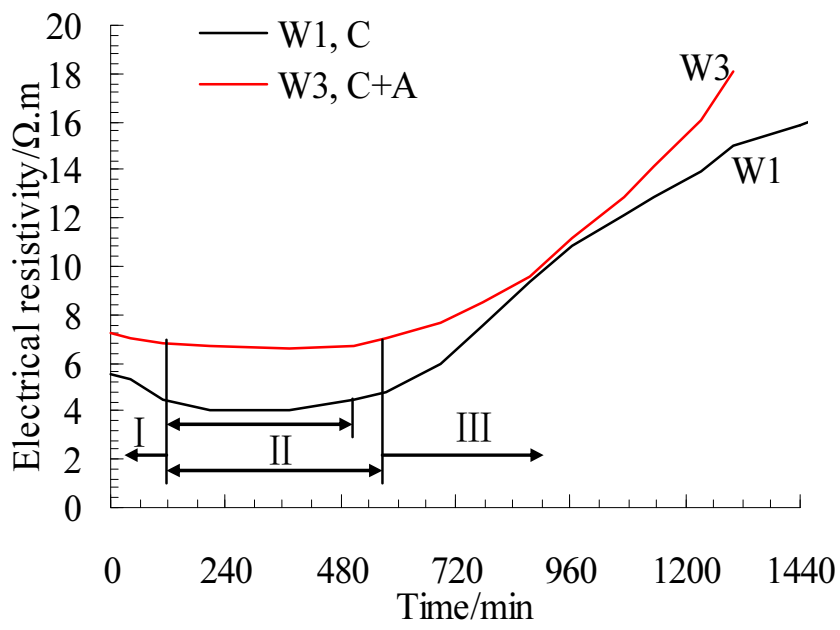

Figure 2. Resistivity evolvement of CA mortar and cement mortar

From Figure 2, it was noted that the development of resistivity in CA mortar was analogous with that in cement mortar, both of which experienced a slight decrease at 
first, then duration of plateau and finally a continual increase. However, the resistivity of CA mortar was obviously higher than that of cement mortar, which might be due to the presence of asphalt in CA mortar.

The hardening process of CA mortar was more complicated than that when only cement was involved as the driving force consisting of cement hydration and asphalt emulsified breaking. The initial descending branch was obviously a consequence of cement hydrolysis as ions such as $\mathrm{Ca}^{2+}, \mathrm{OH}^{-}$and also $\mathrm{SO}^{2-}$ are yielded when the containing gypsum contact with water. The negatively-charged ions accelerated the breaking of asphalt emulsified which was per se positively charged. Asphalt droplets started flocculating and some even deposited on the surface of cement grains, thus slowing cement hydration, which might partly be responsible for the higher resistivity. The following level branch was a result of balance between dissolution and precipitation.

As documented in early reports[10,14], the hydration process of cement-based materials could be categorized into three periods, namely dissolving period, induction period and setting period, all of which could be indicated by the evolvement of resistivity versus time curve. Analogously, the hardening process of CA mortar could also be categorized as such, which corresponded to period I, II and III, respectively in Fig. 2. It was worth noting that the induction period of CA mortar ended 60 min later that that of cement mortar, which might because the minute presence of surfactants in asphalt emulsified retarded the hydration of cement.

\subsection{Effect of W/C on the Early Hardening Process of CA Mortar}

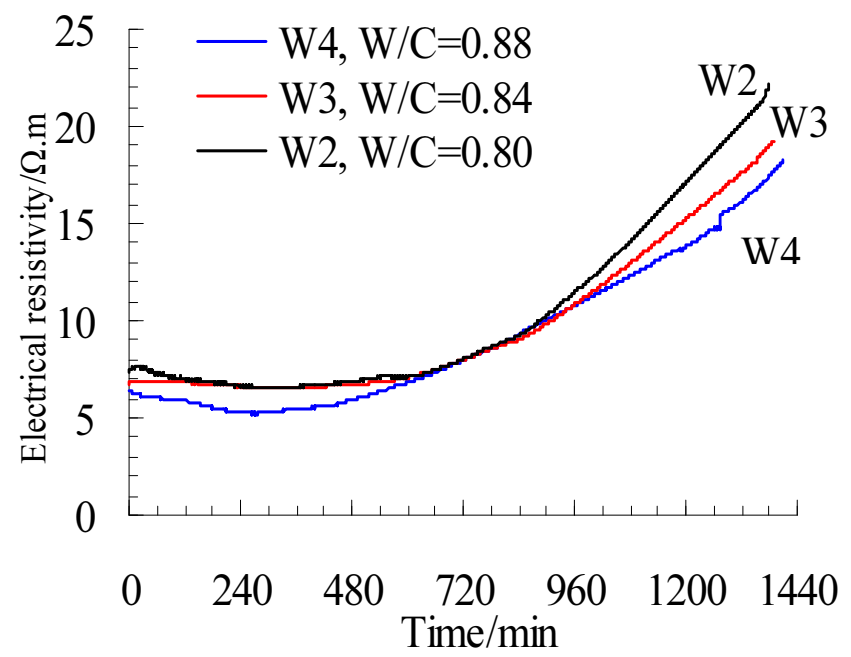

Figure 3. Resistivity evolvement of CA mortar with different W/C.

It can be seen from Figure 3, that with the increasing of $\mathrm{W} / \mathrm{C}$, the resistivity of $\mathrm{CA}$ mortar decreased correspondingly, but not as drastic as that of cement mortar. As the high flowbility of CA mortar called for a remarkably high $\mathrm{W} / \mathrm{C}$ much as 0.80 , in that case, the slight discrepancy in W/C among W2, W3 and W4 contributed little to the resistivity evolvement of CA mortar. 


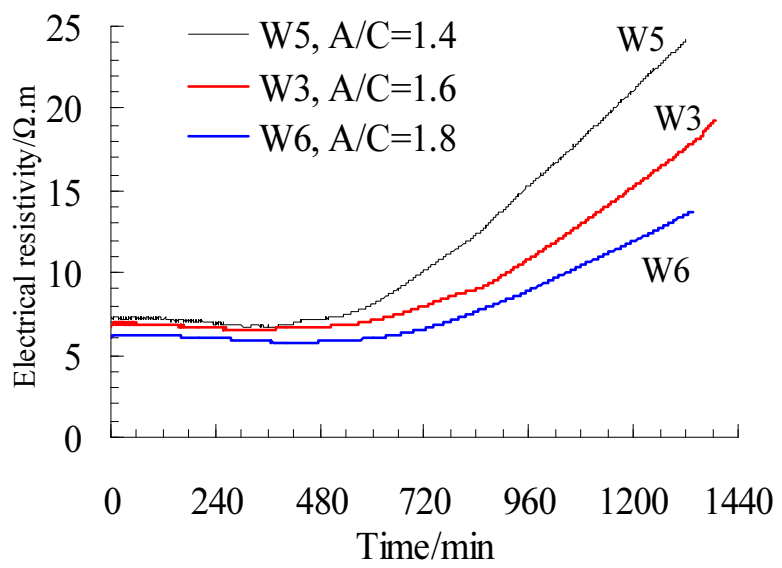

Figure 4. Resistivity evolvement of CA mortar with different A/C.

Figure 4 shows that the electrical resistivity of all CA mortar with different $\mathrm{A} / \mathrm{C}$ value following the same variation pattern: first decreasing and then increasing. It is noted that the higher $\mathrm{C} / \mathrm{A}$ ratio is, the lower electrical resistivity will be. As with the increasing amount of positively charged emulsified asphalt, the concentration of charged particles also increases in early stage mortar. Meanwhile, more emulsifier that could retard the cement is brought into the system, resulting in a slower early stage hardening process of CA mortar and a lower electrical resistivity. Hence, the electrical resistivity of W6 mortar with an A/C of 1.8 increases much slower than that of W5.

\subsection{Effect of Cement Types on the Early Hardening Process of CA Mortar}

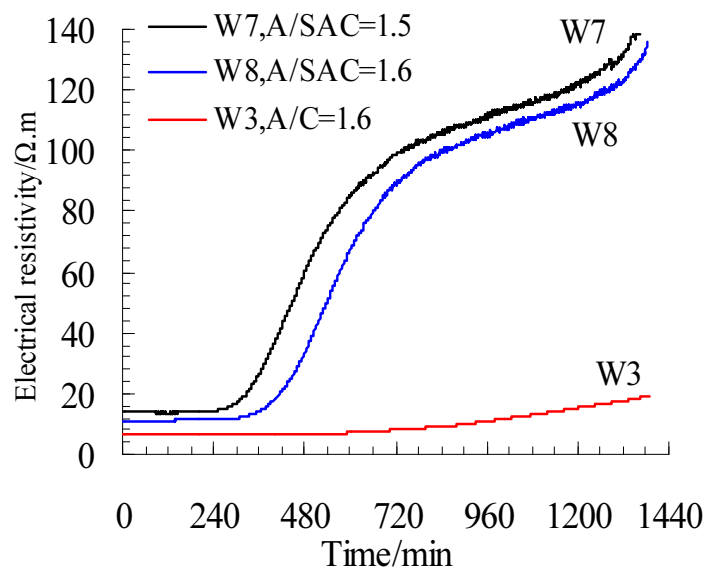

Figure 5. Resistivity evolvement of CA mortar with different cement types.

According to the reference [10], cement was the main source of strength properties in CA mortar and had a remarkable effect on its early hardening process, which was also evidenced in Fig. 6. When SAC was used, the resistivity of CA mortar, especially during setting period, was much higher than that when P.II was used. This was because that the ion concentration yielded in the hydration of SAC was lower than that in the 
hydration of P·II. In addition, the induction period of SAC-CA mortar came to the end $5 \sim 6 \mathrm{~h}$ earlier than that of P-II-CA mortar, indicating that the early hardening process of SAC-CA mortar was much faster. As a result, SAC could be employed in the preparation of early strength CA mortar.

\subsection{The Effects of Silica Fume on Early Stage Hardening}

Because of its small partical size, silica fume is usually used to improve the rheological properties of cement-based paste. The eletracal resistivity versus time of CA mortar with different proportion of silica fume is plot in Figure 6.

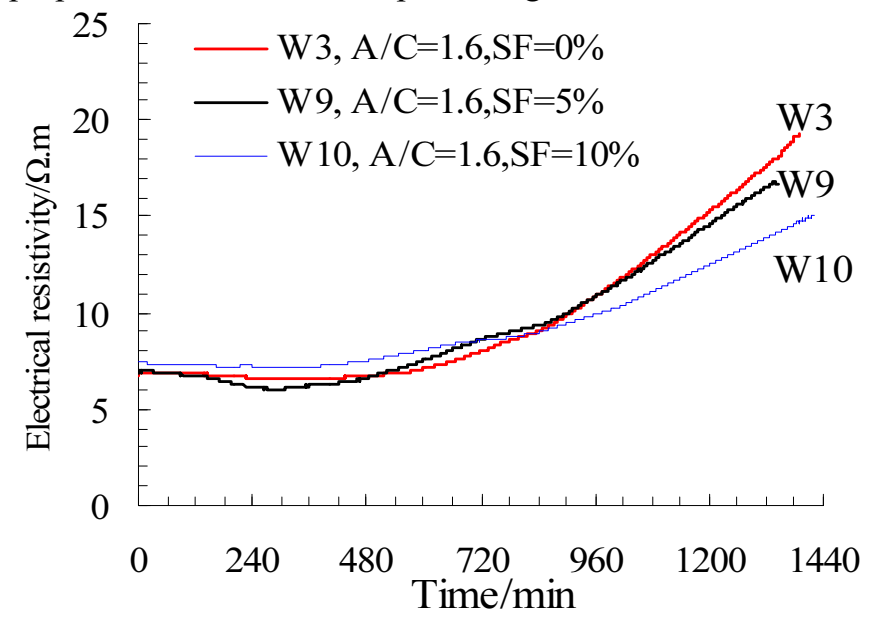

Figure 6. Resistivity evolvement of CA mortar with different silica fume.

Figure 6 indicates that all of the electrical resistivity of CA mortar with different proportion of silica fume first decrease then increase with time. With higher proportion of silica fume, initially electrical resistivity of CA mortar is slightly higher than control group W3 because mineral admixture dilutes the ion concentration in CA mortar, leading to a higher electrical resistivity. While in late stage (approximately after the end of induction period) the electrical resistivity of CA mortar is lower than that of control group W3 due to the high proportion asphalt in the system can prohibit the hydration product from contacting the silica particles, which causing the loss of its early strength properties. In addition, silica fume replaces some of the cement, resulting in slower cementation and hardening of CA mortar and its electrical resistivity is lower than W3 as a result.

\subsection{Application in Practical Engineering}

The low temperature in winter can lengthen the hardening time of CA mortar to more than $24 \mathrm{~h}$ and make it difficult to dismantling template in practical engineering. What's worse, longer hardening time leads to reduction in strength, indicating sands and bubbles will separate out from the homogeneous mortar during the lengthy hardening period. In that case, distress such as peeling and bleeding are predictable effect in practical engineering.

It is found that the winter environment temperature of construction site is lower and range of $1^{\circ} \mathrm{C}$ to $5^{\circ} \mathrm{C}$ in Yangtze river delta area, under this temperature conditions, 
lots of diseases appear in CA mortar layer such as subsidence, peeling and bleeding et al. (Figure 7 and 8).

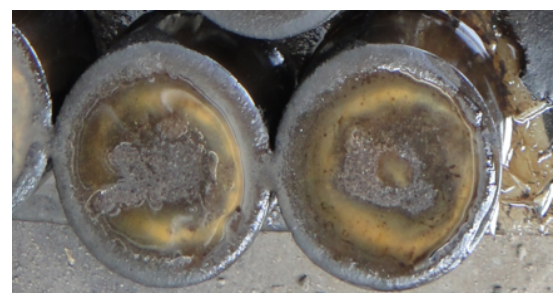

Figure 7. Surface subsidence and bleeding

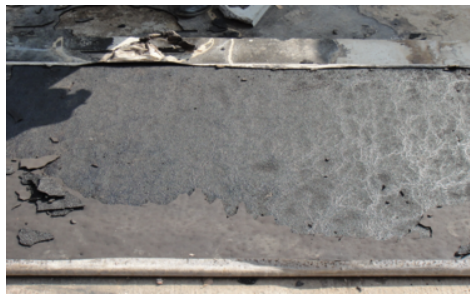

Figure 8. Surface peeling by removing track slab

According to the above research results, the use of sulphoaluminate cement instead of Portland cement can shorten the setting time of CA mortar, and which maybe reduce the risk of diseases in low temperature construction conditions. After sulfur aluminum cement emulsified asphalt mortar (SACA)grouting, the 24h curing temperature of SACA layer is $0 \sim 6^{\circ} \mathrm{Cby}$ continuous monitoring (Figure 9).
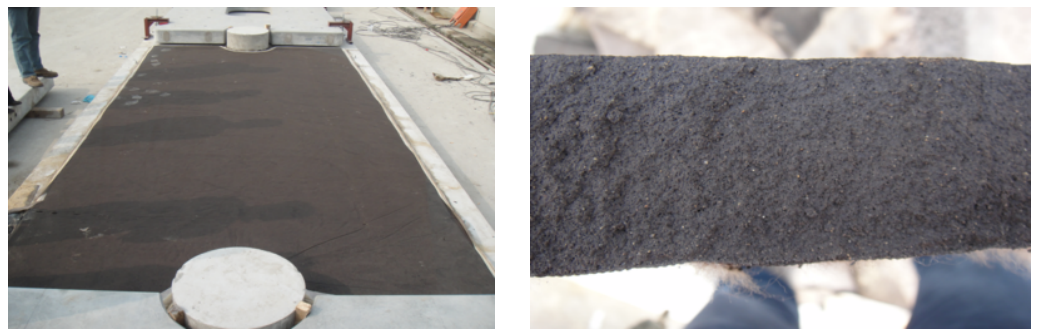

Figure 9. CA mortar evaluation by removing track slab

Figure 9 shows that the section of SACA layer is uniform, the surface is smooth without peeling, which meet the quality requirement of mortar filling board inspection. It is indicated that the preparation of CA mortar suitable for winter construction is feasible by replacing the Portland cement with sulphoaluminate cement.

\section{Conclusions}

(1) The hardening process of CA mortar could be characterized by electrical resistivity versus time curve which was analogous with that in cement mortar, and could be classified into three phases, namely dissolving period, induction period and setting period. The presence of asphalt emulsified retarded the hardening process.

(2) Higher $\mathrm{W} / \mathrm{C}$ and $\mathrm{A} / \mathrm{C}$ extended the induction period; the resistivity of $\mathrm{CA}$ mortar was increased with the increase of $\mathrm{W} / \mathrm{C}$ and $\mathrm{A} / \mathrm{C}$.

(3) The induction period of SAC-CA mortar came to an end 5 6h earlier than that of P-II-CA mortar, and the resistivity of SAC-CA mortar was also higher than that of $\mathrm{P} \cdot \mathrm{II}-\mathrm{CA}$ mortar, indicating that SAC could be employed in the preparation of early strength CA mortar.

(4) Replacement of Portland cementII with sulfoaluminate cement in CA mortar can preventing distress such as peeling and bleeding during construction in winter and conformance to requirements in acceptance standard. 


\section{Acknowledgement}

The research is funded by the National Natural Science Foundation of China (No.51408610).

\section{References}

[1] Ren JJ, Wang J, Li X, et al. Influence of cement asphalt mortar debonding on the damage distribution and mechanical responses of CRTS I prefabricated slab. Construction and Building Materials, 2020(230): $1-12$.

[2] Shao PY, Li HY, Wu SL, et al. Measurement and research on temperature warping of CRTS I track slab and crack between track slab and cement asphalt mortar cushion. China Railway Science, 2013,34(2):18-22.

[3] Zeng XH, Xie YJ, Deng DH, et al. A study of the dynamic mechanical properties of CRTS I type CA mortar,Construction and Building Materials, 2016, 112: 93-99

[4] Ren JJ, Li HL, Cai XP, et al. Viscoelastic deformation behavior of cement and emulsified asphalt mortar in China railway track system I prefabricated slab track. Journal of Zhejiang University-Science A (Applied Physics \& Engineering), 2020,21(4):304-316.

[5] Wang T, Jia HQ, Li HG, et al. Research on water seepage of cement asphalt emulsified (CA) mortar. Construction and Building Materials. 2016 (125):595-599.

[6] Yang JL, Ding WT, Wang ZP, et al. Experimental study on mechanical properties and microstructure of CA mortar under temperature cycle. Journal of Railway Science and Engineering. 2019,16 (3):684-689.

[7] Peng JW, Deng DH, Yuan Q, et al. Study of the rheological behavior of fresh cement emulsified asphalt paste. Construction and Building Materials. 2014, 66: 348-355.

[8] Peng JW, Deng DH, Liu ZQ, et al. Rheological models for fresh cement asphalt paste. Construction and Building Materials. 2014, 71: 254-262

[9] Wang T. Research and Application on CA mortar in ballastless slab track of high speed railway. Wuhan: Wuhan University of Technology,2008:33-70.

[10] Wang FZ, Liu ZC, Hu SG. A novel method to evaluate the setting process of cement and asphalt emulsion in CA mortar. Materials and Structures, 2008,41(4):643-647.

[11] Deng DH, Tian Q, Liu ZQ, et al. Physical structure of cement emulsified bituminous slurry for high speed railway. Science China Press, 2014,44(7):661-671.

[12] Yuan Q, Deng DH, Wang Y. Cement emulsified bituminous mortar for high speed railway. Science China Press, 2020,65(22):2384-2394.

[13] Liu ZQ, Li XN, Tian Q, et al. Microanalysis of development of static mechanical properties of CRTS II cement emulsified asphalt mortar. Science China Press, 2014,44(7):681-686.

[14] Yuan Q, Xie YJ, Peng JW, et al. Key technology of CRTSII slab non-oak track mortar filling layer construction. Railway Construction Technology 2012 (12):14-19.

[15] Xin XZ, Yuan Q, Xie YJ. Discussion on quality Control technology and management of CRTSII plate-type non-tussah track cement emulsion asphalt mortar filling layer. Railway Construction Technology 2012 (12):1-5/13.

[16] Xiao LZ, Li ZJ. Early-age hydration of fresh concrete monitored by non-contact electrical resistivity measurement. Cement and Concrete Research, 2008, 38(3):312-319.

[17] Guo DW, Liao YS, Jiang GX, et al. Research on effect of chemical shrinkage and chloride permeability of cement pastes with air entraining agent by electrical resistivity method. Journal of functional materials, 2019,2(50):2208-2213.

[18] Liao YS, Xu PF, Yang HM, et al. Hydration process of calcium aluminate cement at early age investigated by elcetrical resistivity method. Journal of the chinese ceramic society. 2018,5(46):657-661.

[19] Wei XS, Xiao LZ, Li ZJ. Study on hydration of Portland cement using an electrical resistivity method. Journal of the Chinese Ceramic Society, 2004 (1):34 38.

[20] Liao YS, Wei XS, Penetration resistance and electrical resistivity of cement paste with superplasticizer. Materials and Structures, 2014, 47(4):563-570.

[21] Zhang J, Qin L, Li ZJ, Hydration monitoring of cement-based materials with resistivity and ultrasonic methods. Materials and Structures,2009,(42) 1:15-24. 